Rev. Pat. Trop.25 ( 2 ): 253-262, jul./dez. 1996

\title{
AVALIAÇÃO DA EFICÁCIA DO ALBENDAZOL NA LAGOCHILASCARÍASE MURINA EXPERIMENTAL
}

\author{
Miguel Alipio Vieira', Jayrson Araújo de Oliveira ${ }^{2}$, Carlos Augusto Lopes Barbosa ${ }^{1}$
}

\section{RESUMO}

Para avaliar a ação do albendazol sobre larvas de terceiro estágio de Lagochilascaris minor foram empregados 60 camundongos isogênicos C57BL/6, divididos em três grupos iguais. Cada animal foi inoculado com $10^{3}$ ovos infectantes de $L$. minor, via oral, através de uma sonda esofagiana. Todos os animais dos Grupos I e II foram tratados individualmente com albendazol, na dosagem de $400 \mathrm{mg} / \mathrm{kg} / \mathrm{dia}$, via oral, durante 30 dias. Tendo em vista o padrão de migração de larvas de $L$. minor no organismo de camundongo (hospedeiro intermediário), os animais do Grupo I receberam a droga a partir do $7^{\circ}$ dia e os do Grupo II, no $60^{\circ}$ dia após a inoculação. Os camundongos do Grupo III (controle) não foram tratados com a droga. No $5^{\circ}$ dia após o término do uso da droga, todos os animais de cada grupo foram necropsiados. $\mathrm{O}$ número de larvas vivas recuperadas dos nódulos da musculatura esquelética do tecido celular subcutâneo e das vísceras foi o critério utilizado para avaliar a eficácia da droga. Foram observados níveis de eficácia de $80,9 \%$ para o Grupo I e de $66,3 \%$ para o Grupo II. Podemos inferir que ambos os esquemas terapêuticos utilizados neste trabalho foram ineficazes no tratamento da lagochilascaríase murina experimental.

UNITERMOS: Albendazol. Lagochilascaríase. Terapêutica.

\section{INTRODUÇÃO}

Através do ciclo evolutivo experimental de Lagochilascaris minor, descrito por Campos et al. (1), foram utilizados camundongos e gatos como hospedeiros e cada um destes animais apresentou comportamento diferente. Nos camundongos

\footnotetext{
${ }^{1}$ Professor do Departamento de Parasitologia-Instituto de Patologia Tropical e Saúde Pública/UFG

2 Técnico do Departamento de Parasitologia - IPTSP/UFG.

Endereço para correspondência: Miguel Alípio Vieira - Instituto de Patologia Tropical e Saúde Pública Departamento de Parasitologia - Universidade Federal de Goiás, Rua Delenda Rezende de Melo, s/n, Goiânia-GO, Brasil. E-mail: jayrson@ipe.ufg.br

Recebido para publicação em 15/04/96. Revisto em 13/08/96. Aceito em 20/12/96.
} 
inoculados por via oral com ovos infectantes de $L$. minor, foi observada a eclosão de larvas do terceiro estágio na parede intestinal, com posterior migração das mesmas para o figado, pulmão, musculatura esquelética e tecidos subcutâneos, permanecendo al encistadas (6).

Nos gatos alimentados com camundongos assim infectados, observou-se a presença de formas adultas, larvas e ovos em abscessos da região da faringe, traquéia, tecidos vizinhos (rino e orofaringe), ouvido e tonsilas (1).

A lagochilascaríase tem sido descrita freqüentemente em humanos e o Brasil lidera a casuística mundial $(1,13)$. A ausência de um esquema terapêutico totalmente eficaz na lagochilascaríase humana continua sendo um desafio. Medicamentos, como a dietilcarbamazina, tiabendazol, levamisol, mebendazol e cambendazol têm sido empregados em diferentes dosagens. Entretanto, é comum ocorrerem recidivas das lesões após a cura aparente $(2,8,10,13)$.

Tanto na lagochilascaríase humana como na experimental, a droga utilizada deveria atuar nas várias fases evolutivas do parasito (ovos, larvas e vermes adultos) para se obter um tratamento eficaz, sem possibilidade de recidivas.

Oostburg (10), usando um novo derivado benzimidazólico, o albendazol, obteve resultados promissores ao tratar um caso de lagochilascaríase humana na dosagem de $400 \mathrm{mg} / \mathrm{kg} / \mathrm{dia}$, por um período de 36 dias.

Vieira et al.(14), usando o albendazol na mesma dosagem $(400 \mathrm{mg} / \mathrm{kg})$, por 30 dias consecutivos, sobre ovos embrionados e ovos não embrionados (in vitro), verificaram que a droga impedia a embriogênese dos ovos.

Os resultados promissores apresentados por esses autores nos incentivaram a investigar a ação deste medicamento, por um período de 30 dias, sobre larvas encistadas nos tecidos e vísceras de camundongos infectados experimentalmente.

\section{MATERIAL E MÉTODO}

\section{Parasito}

Fêmeas adultas de L. minor, recuperadas de gatos infectados experimentalmente, foram dissecadas e delas retiradas as alças uterinas contendo ovos. Estes foram colocados em placas de Petri com solução de formol a $1 \%$ e deixados por um período de 40 dias à temperatura ambiente, para obtenção do estágio infectante.

Após esse período, os ovos larvados foram transferidos para tubos de centrifugação graduados, a suspensão foi homogeneizada e retiraram-se cinco
VIEIRA, M.A.; OLIVEIRA, J.A.; BARBOSA, C.A.L. Avaliação da eficácia do albendazol na lagochilascaríase murina experimental. Rev. Pat. Trop.25 (2 ): 253-262, jul./dez. 1996

alíquotas de $0,01 \mathrm{ml}$ da mesma, contendo ovos, os quais foram examinados entre lâmina e lamínula, com auxílio de microscópio óptico.

Os ovos infectantes foram contados e a média das cinco contagens determinou a concentração de ovos por $\mathrm{ml}$.

\section{Animais}

Foram usados 60 camundongos C57BL/6, obtidos do Biotério do Departamento de Parasitologia do Instituto de Patologia Tropical e Saúde Pública da Universidade Federal de Goiás.

\section{Infecção dos animais}

Cada animal foi inoculado com $10^{3}$ ovos infectantes de $L$. minor, através de sonda esofagiana.

\section{Esquemas de tratamento}

Os animais foram divididos em dois grupos iguais e submetidos aos seguintes esquemas de tratamento com albendazol:

Grupo I - 20 animais tratados individualmente com $400 \mathrm{mg} / \mathrm{kg}$, durante 30 dias, a partir do $7^{\circ}$ dia após a infecção;

Grupo II - 20 animais tratados individualmente com $400 \mathrm{mg} / \mathrm{kg}$, durante 30 dias, a partir do $60^{\circ}$ dia após a infecção.

Cada grupo teve como controle 10 animais infectados, porém não tratados.

No $5^{\circ}$ dia após o término da administração da droga para cada grupo, todos os animais foram necropsiados. O número de larvas vivas recuperadas dos nódulos da musculatura esquelética, do tecido subcutâneo e de vísceras constituiu o critério para avaliar a eficácia da droga.

\section{Avaliação da eficácia}

A avaliação da eficácia da droga foi feita pela relação entre a média de larvas vivas obtidas na necrópsia do grupo-controle, com a média do grupo tratado, aplicando-se a fórmula (Pumarola et al.(11)) a seguir. 


$$
E \%=\frac{X L C-X L T}{X L C}
$$

\section{$\mathrm{E} \%$ = percentual de eficácia}

$\mathrm{XLC}=$ média de larvas vivas recuperadas no grupo-controle

$\mathrm{XLT}=$ média de larvas vivas recuperadas no grupo tratado

\section{RESULTADOS}

Os resultados desse trabalho estão apresentados na Tabela 1, indicando o número de larvas vivas recuperadas dos camundongos tratados no $7^{\circ}$ e $60^{\circ}$ dia após a inoculação (Grupos I e II). Na Tabela 2 figura o número de larvas vivas recuperadas dos animais dos grupos-controle.

Tabela 1. Número de larvas vivas recuperadas em camundongos dos Grupos I e II, inoculados com $10^{3}$ ovos de L. minor, tratados com albendazol durante 30 dias e necropsiados no $5^{\circ}$ dia após o término do tratamento

\begin{tabular}{ccccc}
\hline Grupo & $\begin{array}{c}\text { Número de } \\
\text { animais }\end{array}$ & $\begin{array}{c}\text { Número total de } \\
\text { larvas }\end{array}$ & $\begin{array}{c}\text { Média de larvas } \\
\text { recuperadas por animal }\end{array}$ & $\begin{array}{c}\text { Eficácia } \\
(\%)\end{array}$ \\
\hline I & 20 & 57 & 2,85 & 80,87 \\
II & 20 & 91 & 4,55 & 66,29 \\
\hline
\end{tabular}

Foi observado que nos animais do Grupo I, tratados no $7^{\circ}$ dia após a inoculação (DAI), houve uma eficácia da droga de 80,87\% (Figura 1).
VIEIRA, M.A.; OLIVEIRA, J.A.; BARBOSA, C.A.L.. Avaliação da eficácia do albendazol na lagochilascariase murina experimental. Rev. Pat. Trop.25 (2 ): 253-262, jul./dez. 1996

Nos animais do grupo II, tratados no $60^{\circ}$ dia após a inoculação, a eficácia da droga foi de $66,29 \%$ (Figura 2).

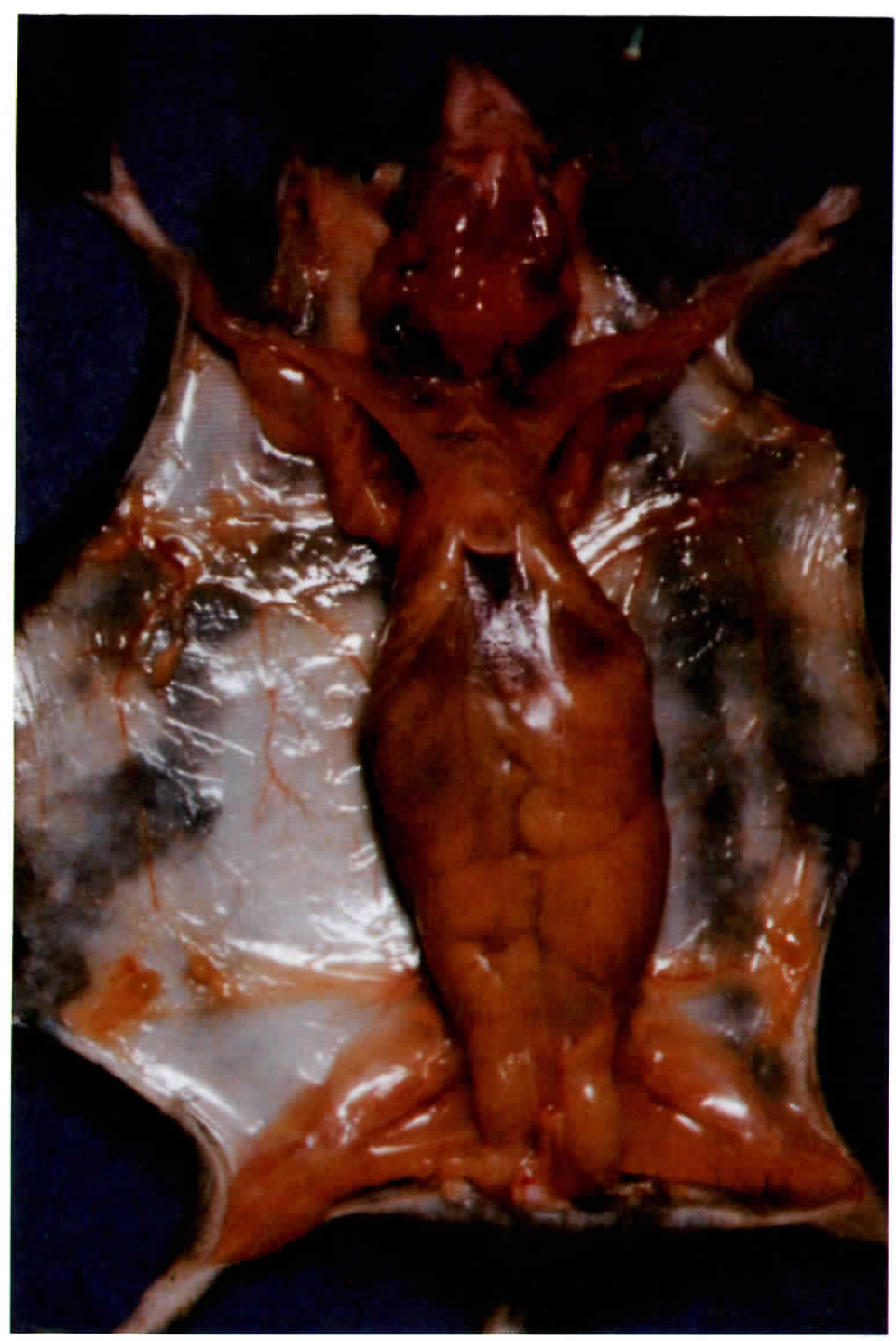

Figura 1. Camundongo inoculado com $10^{3}$ ovos de L. minor e tratado com albendazol no $7^{\circ} \mathrm{DAI}$ 


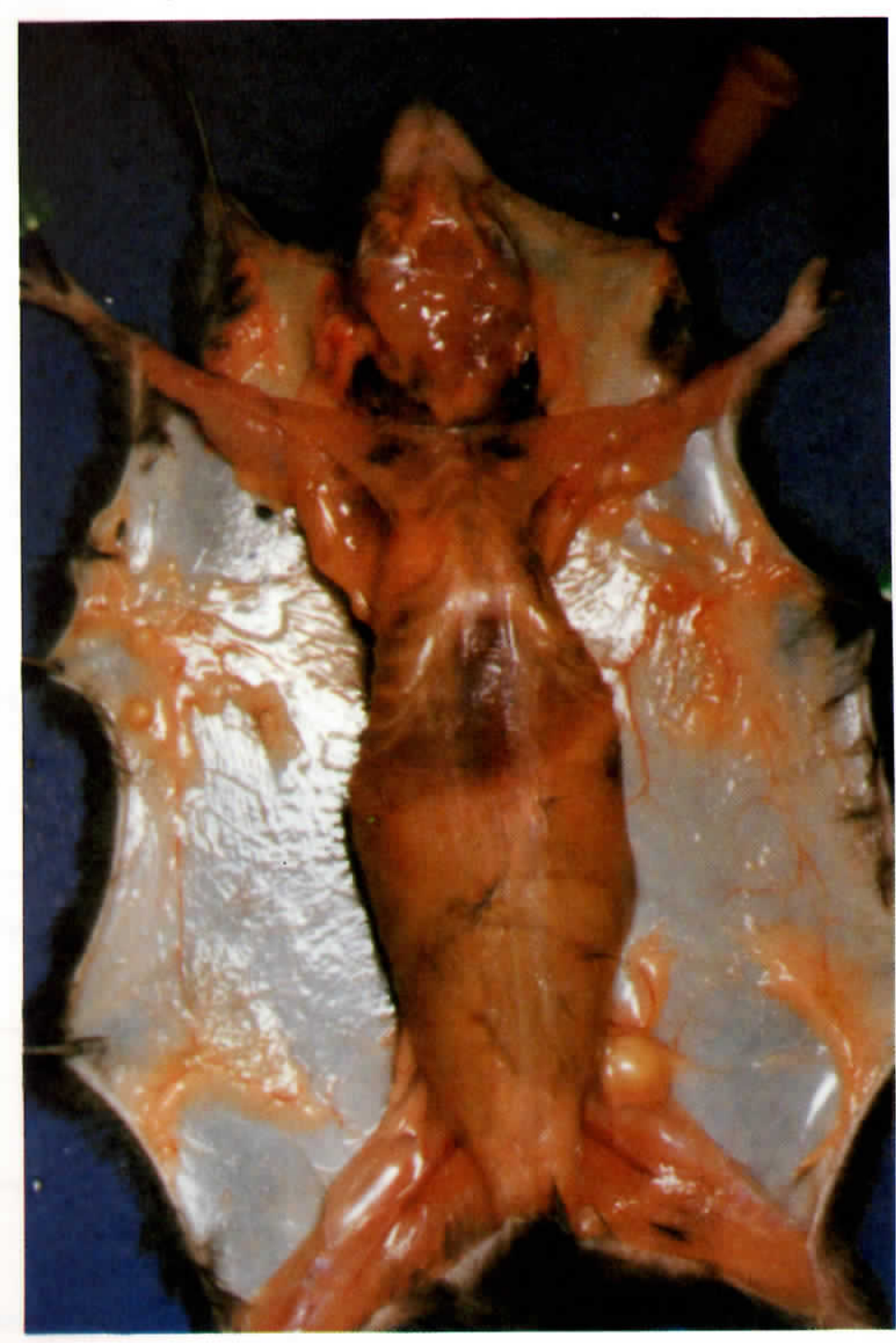

Figura 2. Camundongo inoculado com $10^{3}$ ovos de L. minor e tratado com albendazol no $60^{\circ} \mathrm{DAI}$

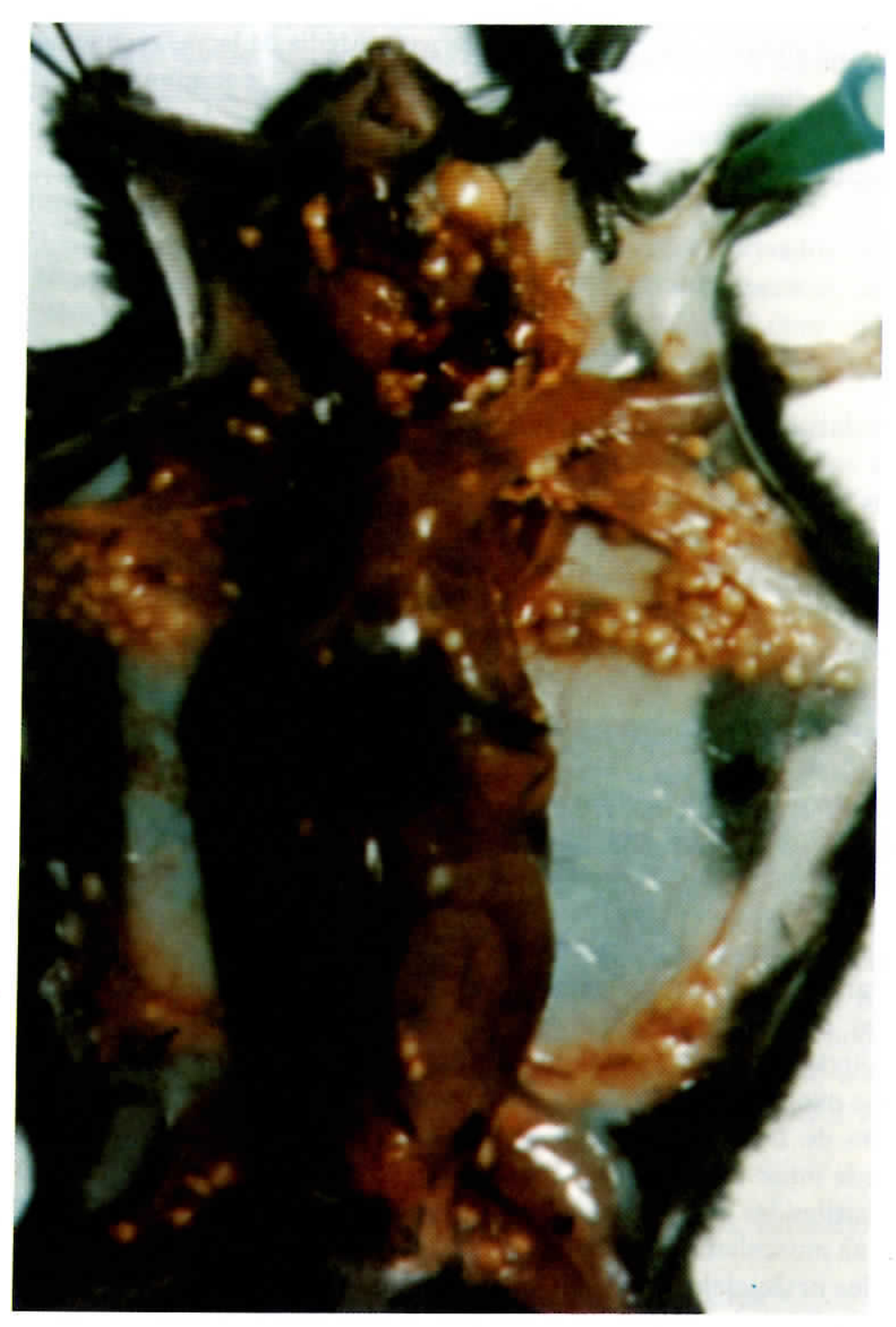

Figura 3. Camundongo inoculado com $10^{3}$ ovos de $L$. minor. Grupo-controle 
VIEIRA, M.A.; OLIVEIRA, J.A.; BARBOSA, C.A.L. Avaliação da eficácia do albendazol na lagochilascariase murina experimental. Rev. Pat. Trop.25 (2 ): 253-262, jul./dez. 1996

Tabela 2. Número de larvas vivas recuperadas em camundongos dos Gruposcontrole, inoculados com $10^{3}$ ovos de $L$. minor e necropsiados junto com cada Grupo tratado

\begin{tabular}{cccc}
\hline Grupo & Número de animais & Número total de larvas & $\begin{array}{c}\text { Média de larvas recuperadas } \\
\text { por animal }\end{array}$ \\
\hline I & 10 & 149 & 14,9 \\
II & 10 & 135 & 13,5 \\
\hline
\end{tabular}

\section{DISCUSSÃO}

O albendazol é um derivado benzimidazólico de rápida absorção intestinal. Sabe-se que ele exerce sua atividade anti-helmíntica por inibição da polimerização dos túbulos das células dos helmintos, tendo como conseqüência o bloqueio da captação de glicose nos nematódeos. Assim, os níveis de energia tornam-se incompatíveis com a sobrevida do parasito (5).

Estudos clínicos mostraram que o albendazol exibe atividade vermicida, ovicida, larvicida e é efetivo na ascaridiose, enterobiose, ancilostomoses (Necator americanus e Ancylostoma duodenale), teníase, estrongiloidose experimental (Strongyloides venezuelensis), angiostrongiloidose por Angiostrongylus cantonensis e larva migrans $(3,4,7,9,12)$.

$\mathrm{O}$ albendazol tem sido utilizado nas várias fases de desenvolvimento da lagochilascaríase. Oostburg(10) obteve sucesso ao tratar o sexto caso humano de lagochilascaríase, no Suriname, com albendazol, na dosagem de $400 \mathrm{mg} / \mathrm{kg}$, por um período de 36 dias. Vieira et al.(14) testaram a eficácia in vitro deste medicamento na mesma dosagem, sobre ovos recém-eliminados e ovos já embrionados de $L$. minor, e verificaram que nesta dosagem a droga impede a embriogênese sobre ovos não embrionados, porém não age sobre os ovos larvados.

$\mathrm{Na}$ utilização da via oral para a inoculação de camundongos na lagochilascaríase experimental, proposta por Campos et al.(l), observa-se eclosão de ovos e liberação de larvas de terceiro estágio no intestino delgado. Estas larvas perfuram a parede intestinal, alcançam a circulação sangüínea, passam pelo fígado e pulmões, são distribuídas para a grande circulação e terminam por serem encistadas, principalmente na musculatura esquelética e no tecido celular subcutâneo.

Baseados nesse ciclo, dividimos o experimento em dois grupos distintos. Os animais do Grupo I foram tratados no $7^{\circ}$ dia após a inoculação, quando as larvas se encontram em migração pelo organismo do hospedeiro. Nesse grupo de animais
VIEIRA, M.A.; OLIVEIRA, J.A.; BARBOSA, C.A.L. Avaliaçăo da efiḉcia do albendazol ma lagochilascarlase murina experimental. Rev. Pat. Trop.25 (2 ): 253-262, jul./dez. 1996

observamos ainda que houve uma maior ação do medicamento, apresentando uma eficácia de $80,87 \%$, provavelmente porque as larvas nesta fase do ciclo evolutivo não estejam protegidas pela membrana cística.

Já nos animais do Grupo II, tratados no $60^{\circ}$ dia após a inoculação, quando as larvas já se apresentam encistadas na musculatura, o medicamento apresentou uma eficácia terapêutica de apenas $66,29 \%$. Presume-se que a cápsula que protege a larva constitua uma barreira, impedindo ou diminuindo a ação do medicamento sobre ela.

Esses resultados sugerem que ambos os esquemas terapêticos empregados não apresentaram eficácia satisfatória.

Em estudos futuros, com o aprimoramento dos derivados benzimidazólicos e alterações nas vias de administração, ou mesmo um esquema terapêutico mais adaptável à biologia do parasito, poder-se-á ter uma atuação mais eficiente da droga na cápsula conjuntiva a qual age, supostamente, protegendo o parasito.

\section{SUMMARY}

\section{Evaluation of the efficacy of albendazol in the murine experimental lagochilascariasis}

Sixty inbred C57BL/6 mice were allocated into 3 equal groups, for the evaluation of the action of albendazol on 3rd stage Lagochilascaris minor larvae. Each animal was inoculated with $10^{3}$ infecting eggs of $L$. minor, through an esophageal probe. All animals in groups I and II were treated with albendazol 400 $\mathrm{mg} / \mathrm{Kg} /$ day by 30 days. Animals in group I received the drug on the 7 th day and in group II on the 60th day post inoculation, due to the migration pattern of $L$. minor larvae on the mouse organism. The mice in group III (controls) did not receive the drug. All animals were sacrificied on the 5th day post drug ingestion. The criteria used for the evaluation of the efficacy of the drug was the number of living larvae retrieved from striated muscle, subcutaneous tissue and viscus nodules. Efficacy levels of $80,9 \%$ for group I and $66,3 \%$ for group II were observed. We conclude that both therapeutic protocols used were ineffective in the treatment against murine experimental lagochilascariasis

KEYWORDS: Albendazol. Experimental lagochilascariasis. Efficacy.

\section{REFERÊNCIAS BIBLIOGRÁFICAS}

01.Campos, D.M.B., Freire-Filha, L.G., Vieira, M.A., Paçô, J.M, Maia, M.A Experimental life cycle of Lagochilascaris minor Leiper, 1909. Rev. Inst. Med. trop. Säo Paulo, 34: 277-287, 1992. 
VIEIRA, M.A.; OLIVEIRA, J.A.; BARBOSA, C.A.L. Avaliação da eficácia do albendazol na lagochilascariase murina experimental. Rev. Pat. Trop.25 (2 ): 253-262, jul./dez. 1996

02.Chieffi, P.P., Frucchi, H., Proença, N.G.,Pereira,W.A., Paschoalotti, M.A. Infecção cutânea por Lagochilascaris minor: tratamento e cura rápida pelo levamisol. An. Bras. Derm, 56: 141-144, 1981.

03.Cline, B.L., Little, M.D., Bartholomeu, R.K., Halsey, N.A. Larvicidal activity of albendazol against N. americamus in human volunteers. Am. J. Trop. Med. Hyg., 33:387-394, 1986.

04.Cruz, M., Cruz, I., Horton, J. Albendazol versus praziquantel in the treatment of cerebral cysticercosis clinical evaluation. Trans. Roy. Soc. Trop. Med. Hyg., 85:244-247, 1991.

05.Delgado, O., Botto, C., Mattei, R., Escalante. A. Effect of albendazole in experimental toxocariasis of mice. Ann. Trop. Med. Parasitol., 83: 621-624, 1989.

06.Freire-Filha, L. G., Campos, D. M. B. Consideraçð̃es sobre o desenvolvimento de Lagochilascaris minor Leiper, 1909, em camundongos isogênicos da linhagem $\mathrm{C}_{57} \mathrm{Bl} / 6$. Rev. Pat. Trop. 21: 219-233, 1992.

07.Hwang, Kao-Ping, Chen, Eng-Ping. Larvicidal effect of albendazole against Angiostrongylus cantonensis in mice. Am. J. Trop. Med. Hyg., 39: 191-195, 1988.

08.Leão, R.N.Q., Fraiha-Neto, H., Faiha, S.C., Tonini, K.C., Silva, J.A.P.R. Perspectivas do emprego do cambendazol na lagochilascaríase. In: XXI Congresso da Sociedade Brasileira de Medicina Tropical. Programas e resumos. São Paulo. p. 76. 1985.

09.Neto, V.A., Pinto, P.L.S., Moreira, A.A.B., Campos, R, Santana, E.J., Levai, E.V., Padilha, L.A.A., Takigutti, C.K. Avaliação da atividade terapêutica de albendazol em ratos experimentalmente infectados com Strongyloides venezuelensis. Rev. Inst. Med. trop., São Paulo., 28: 181-184, 1986.

10.Oostburg, B.F.J. The sixth case of Lagochilascaris minor in Surinam. Trop. Geogr. Med., 44: 154-159, 1992.

11.Pumarola, D., Alonso, M.T., Berenguer, F.J., Gallego, J. Ensayo de la actividad antihelmintica de productos de nueva sintesis derivados del 2-iminotiazol y del 2-iminotiadiazol. III. Actividad anguilulicida. Rev. Iber. Parasitol., 4: 403-408, 1987.

12.Torres, J.R., Orhuela, A.R., Garcia, D., Abdul-Hadi, S. Treatment of cutaneous larva migrans with albendazole: preliminary report. Rev. Inst. Med. trop., São Paulo., 31:56-58, 1989.

13.Veloso, M.G.P., Corini, D.F., Mendonça, J.L.F. Lagochilascaríase humana, sobre três casos encontrados no Distrito Federal, Brasil. Rev. Inst. Med. trop. São Paulo, 34: 597- 591, 1992.

14.Vieira, M.A., Oliveira, J. A., Barbosa, C. A. L., Campos, D. M.B. Atividade anti-embriogênica "in vitro" do albendazol sobre ovos de Lagochilascaris minor Leiper, 1909. Rev. Pat. Trop. 23: 221-227, 1994. 